\title{
Waiting Time in Emergency Department in Riyadh 2017
}

\author{
Charles A. Villanueva, Mohammed Almadani*, Fahad Mahnashi, Saad Alyhya, Osama Alshreef \\ College of Medicine, King Saud University, Riyadh, Saudi Arabia \\ Email: ^dr.al_madani@hotmail.com
}

How to cite this paper: Villanueva, C.A., Almadani, M., Mahnashi, F., Alyhya, S. and Alshreef, O. (2017) Waiting Time in Emergency Department in Riyadh 2017. Journal of Biosciences and Medicines, 5, 55-60. https://doi.org/10.4236/jbm.2017.53006

Received: January 27, 2017

Accepted: March 19, 2017

Published: March 22, 2017

Copyright (๑) 2017 by authors and Scientific Research Publishing Inc. This work is licensed under the Creative Commons Attribution International License (CC BY 4.0).

http://creativecommons.org/licenses/by/4.0/ (c) (i) Open Access

\begin{abstract}
Aim: To investigate the waiting times in the emergency department of both private and public hospitals. Methods: The study employs theoretical, qualitative, and quantitative approaches to come up with conclusions that are reliable. A total of 473 participants who had a direct interaction with the emergency department were asked to provide data on the waiting time, the kind of hospital they went to, the symptoms they had, and their gender for evaluation purposes. Common symptoms identified to the patients visiting the emergency department are related to head and neck, chest, abdominal pains, genitals, limbs, and back. It was found that more patients visited public hospitals over private hospitals. Additionally, more patients had symptoms related to abdominal than any other of the common symptoms and more males than females participated in the research. Data recording is done in tables using MS Excel and data presented through analysis using bar graphs for comparative purposes. Conclusion: Based on the results of the research, it was concluded that the efficiency of the emergency department is below the recommended standards. Finally, the recommendations made from the research findings included an audit of the emergency departments, increasing the staff in the department, and more research should be conducted throughout the country to come up with a more reliable record that is more inclusive.
\end{abstract}

\section{Keywords}

Waiting Time, Emergency Departments, Riyadh, Saudi Arabia

\section{Introduction}

In the course of execution of medical attention to a patient, time is of the essence if one is to save a life as argued by Hamilon [1]. In an emergency department, there should be aminimum amount of time spent receiving the patient to the time medication is administered. In this research, we seek to investigate the 
waiting time in the emergency department so that necessary recommendations can be proposed to improve the efficiency of the system. The research covers both genders of male and female representatives that were randomly selected and predetermined questions asked to them to collect data on their emergency experience. Another reason that also makes this research important is to establish efficient methods of receiving patients coming to the emergency department to reduce the waiting time and improve the urgency in which the department handles the patients [2].

The evidence on the impact of waiting times has focused on high acuity patients. Long waiting times are associated with delays in time sensitive treatments for serious conditions typically requiring admission to hospital [3]. About $85 \%$ of patients attending an emergency department, however, go home after their visit, and whether waiting times adversely affect their outcomes is unknown. Long waiting times can delay every stage of the visit, from initial assessment to treatment to final decision making to admission or discharge (patient disposition) and can alter clinicians' routines and decision making. For patients, the frustration with long waits can cause up to $10 \%$ to leave without being seen (that is, before seeing a physician, without a diagnosis or treatment). Hence, long waiting times can alter the behaviour of both staff and patients and lead to potentially adverse consequences [4].

The current study aimed to explore the waiting times in the emergency department of both private and public hospitals.

\section{Methodology}

A retrospective cross-sectional method of data collection was used randomly among both males and females, and questions were asked to them on past experiences at an emergency department. The total number of participants in the survey was 473 that were comprised of 251 males and 222 females. For the purpose of collecting data from the participants, Taylor, Marcus, Virtue, \& McDonald [5], recommend that both survey and questionnaires were used to provide reliable information and have some comparative basis. The participants were also classified into smaller groups that would present a much easier task for recording and analysis. Groups were dictated by the age of the participants which also ranged between 20 and 60 years. The reason for particularly choosing this age group is that these are the people who have either been in the emergency department themselves or have taken a patient to the emergency section and became victims of the wait in the department.

Another important data that was collected was the mode of arrival to the hospital according to Becker \& Douglass [6]. Participants were asked whether they came by ambulance or not since it is the safest method of getting a patient to the hospital. The time of waiting in the emergency department was also collected to provide a clear understanding of the figures on the ground. In the questionnaire, participants were required to fill in the time gaps divided where the time was between 5 minutes, 10 minutes, 15 minutes, 20 minutes, 30 minutes, 40 minutes, 
50 minutes, 1 hour, and more than 1 hour. This time described the duration of time between the arrivals at the emergency department to the time when medical care is provided to the patient. Moreover, the type of hospital the participants were in was needed whether it was a private or public hospital.

Equally important, the nature of the symptoms of the patients who were the research participants had was also recorded. Several symptoms were identified as the benchmark in the research data collection. Among the symptoms recorded include those related to head and neck, chest, abdominal parts, the genital parts, genital parts, limbs, and the back such as pain and a sharp reduction in movements, etc. In addition to this, the services given to patients after receiving medical attention is also of great importance. Because of this, patients also had to provide information about their encounters with reference to the provision of after health services such as medical follow-up that would ensure a full recovery [7]. Once the data was collected, it was recorded in tables using Microsoft excel software which would then give data analysis an easier task.

\section{Results and Discussions}

From the research procedure stated above, the data collected is recorded in the tables below. The relevant data that was recorded include the age groups of the participants, waiting time from arrival to medical attention, and the patients who received after health services after receiving medical attention and discharged from the emergency department [8]. According to the findings of the patients on hospitals they attended, 359 went to public hospitals while 114 patients went to private hospitals. Figure 1 below shows the data on patients visiting the private and public hospitals.

Table 1 shows the demographics of participant visit to the emergency department based on their ages. The high age average was among those from $36-40$ years, this agree with the results of McCaig, Linda, and Catharine [9], who conducted a National hospital ambulatory medical care survey.

Moreover, data collected on the nature of symptoms the participants had when they visited the emergency department is recorded in Table 2. Abdo-

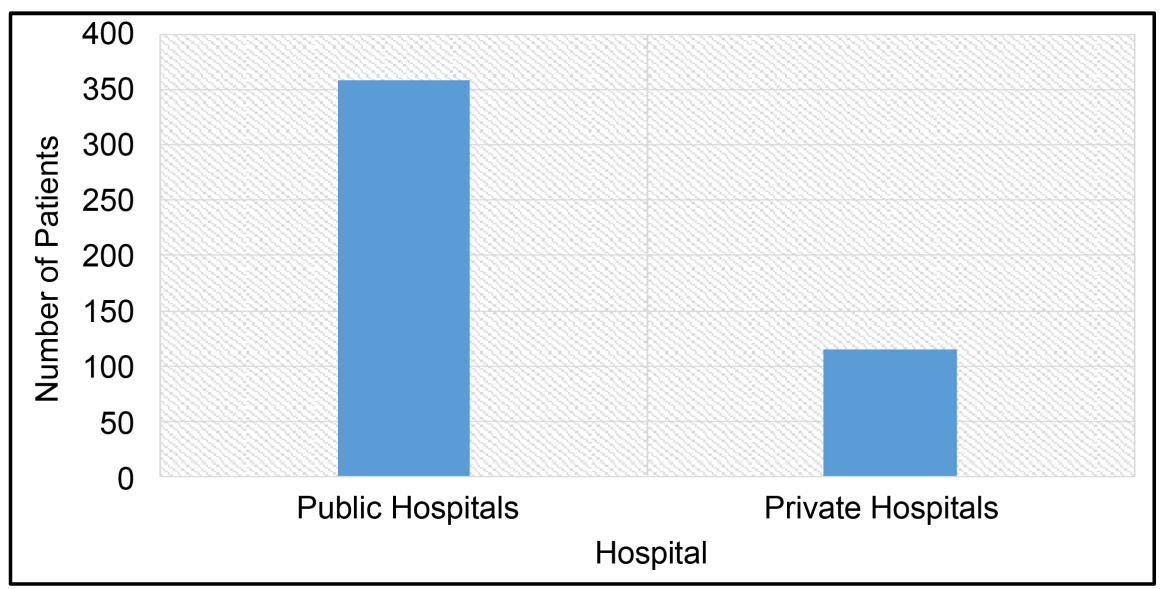

Figure 1. Graphical representation of hospital visit number. 
minal pain was the most common symptom and this agrees with the study findings of Graff, Louis G., and Dave Robinson [10].

Nevertheless, Table 3 shows the waiting times of the participants in the emergency department which were divided into 9 groups from 5 minutes to more than 1 hour according our questionnaire.

Table 4 shows the symptoms that were addressed within the first 10 minutes in the emergency department.

Based on the data collected and presented in the tables and charts above, clear observations can be made. Most of the participants that visited the emergency department are aged between 36 - 40 years. Most importantly, the waiting times between arrivals and administration of medical attention for the participants also revealed great information. It is clear that majority of the patients arriving in the emergency department have to wait for between 5 to 15 minutes, representing 263 of the 473 participants. This shows that the hospitals are just more than 50\% efficient in managing the patients arriving in the department. Also, as explained by Chaudhury, Mahmood, \& Valente [11], patients arriving in the department have head and neck and back pains, a typical case with the patients in the age group of 36 to 40 years.

\section{Conclusions}

Undoubtedly, the results obtained from the survey indicate that there are major delays in delivering medical services to patients in the emergency department. More than $40 \%$ of the participants recorded that they waited for more than 20 minutes before getting the necessary medical attention. These results reveal that the services delivered in the emergency department do not meet the quality standards because, with these delays, many patients are prone to be exposed to

Table 1. Patient demographics of visiting the emergency department.

\begin{tabular}{ccccccccc}
\hline AGE & $20-25$ & $26-30$ & $31-35$ & $36-40$ & $41-45$ & $46-50$ & $51-55$ & $56-60$ \\
\hline NUMBER & 53 & 72 & 64 & 88 & 67 & 48 & 53 & 48 \\
\hline
\end{tabular}

Table 2. Number of participants and nature of their symptoms.

\begin{tabular}{cccccccc}
\hline Nature of Symptoms & Head and Neck & Chest & Abdominal & Genitals & Limbs & Back \\
\hline Number of participants & 73 & 82 & 139 & 43 & 67 & 69 \\
\hline
\end{tabular}

Table 3. Waiting times for participants in emergency department.

\begin{tabular}{|c|c|c|c|c|c|c|c|c|c|}
\hline Waiting Time & 5 mins & 10 mins & 15 mins & 20 mins & 30 mins & 40 mins & 50 mins & 1 hour & $>1$ hour \\
\hline $\begin{array}{c}\text { No. of } \\
\text { Participant }\end{array}$ & 84 & 107 & 72 & 51 & 63 & 42 & 37 & 12 & 5 \\
\hline
\end{tabular}

Table 4. Symptoms address rankings at the emergency department.

\begin{tabular}{cccccccc}
\hline Nature of Symptoms & Head and Neck & Chest & Abdominal & Genitals & Limbs & Back \\
\hline Number of participants & 108 & 107 & 113 & 78 & 41 & 26 \\
\hline
\end{tabular}


fatal conditions. Additionally, it was realized that as much as emergency services should be addressed with high efficiency and speed, some patients had to wait for more than 1 hour, and in most cases, this might lead to fatalities since it is relatively difficult to save the life. There are various factors responsible for this delayed period of disposal which is categorized further ranging from conveyance problem, consultation delay etc. A study was conducted by Abdullah [12], in a hospital in Malaysia to determine the emergency department waiting time and to investigate possible operational factors responsible for patients waiting period in the outpatient department of a hospital. The study revealed that there are various factors responsible for waiting period such as registration procedure, number of staff at counter and insufficient doctors.

Therefore, it can be concluded that the efficiency of the emergency department does not meet the standards described by McNew, Di Lima, Forsyth, \& Gillis [13] and should, therefore, be improved greatly.

\section{Recommendation}

The results obtained from this research cannot be used to make a concrete conclusion about the overall performance of emergency departments in the country. As a result, I would recommend that more research should be conducted using better data collection methods and analysis tools so that a more accurate result can be obtained. Moreover, the data collection should be done among many participants so that a wider range of comparisons can be made and suitable action taken to rectify the problem. Nevertheless, to the emergency department, a complete audit should be conducted so that the performance of workers can be analyzed. Also, equipment, as well as staffing of the department, needs to be improved as it would lead to a corresponding increase in the efficiency of the department. Increasing the staff number in the emergency department ensures that there are always people to take care of the incoming patients and reduce the waiting time hence more efficiency.

\section{References}

[1] Hamilton, W.F. (1974) Systems Analysis in Emergency Care Planning. Medical Care, 12, 152-162. https://doi.org/10.1097/00005650-197402000-00005

[2] Shryock, T. (2004) Health and Medical Red Zone: How Akron City Hospital Uses Infrared Technology to Track Patients and Equipment. Smart Business Akron/ Canton.

http://www.sbnonline.com/Local/Article/5689/65/0/Red_zone.aspx?Category=112

[3] Diercks, D.B., Roe, M.T., Chen, A.Y., Peacock, W.F., Kirk, J.D., Pollack, C.V., Gibler, W.B., Smith, S.C., Ohman, M. and Peterson, E.D. (2007) Prolonged Emergency Department Stays of Non-ST-Segment-Elevation Myocardial Infarction Patients Are Associated with Worse Adherence to the American College of Cardiology/American Heart Association Guidelines for Management and Increased Adverse Events. Annals of Emergency Medicine, 50, 489-496. https://doi.org/10.1016/j.annemergmed.2007.03.033

[4] Mohsin, M., Forero, R., Ieraci, S., Bauman, A. E., Young, L. and Santiano, N. (2007) A Population Follow-Up Study of Patients Who Left an Emergency Department 
without Being Seen by a Medical Officer. Emergency Medicine Journal, 24, 175-179. https://doi.org/10.1136/emj.2006.038679

[5] Taylor, D., Kennedy, M.P., Virtue, E. and McDonald, G. (2006) A Multifaceted Intervention Improves Patient Satisfaction and Perceptions of Emergency Department Care. International Journal for Quality in Health Care, 18, 238-245.

https://doi.org/10.1093/intqhc/mzl002

[6] Becker, F. and Douglass, S. (2008) The Ecology of the Patient Visit: Physical Attractiveness, Waiting Times, and Perceived Quality of Care. The Journal of Ambulatory Care Management, 31, 128-141.

https://doi.org/10.1097/01.JAC.0000314703.34795.44

[7] Ulrich, R.S., Zimring, C., Zhu, X., DuBose, J., Seo, H.-B., Choi, Y.-S., Quan, X. and Joseph, A. (2008) A Review of the Research Literature on Evidence-Based Healthcare Design. HERD: Health Environments Research \& Design Journal, 1, 61-125. https://doi.org/10.1177/193758670800100306

[8] Thompson, D.A., Yarnold, P.R., Williams, D.R. and Adams, S.L. (1996) Effects of Actual Waiting Time, Perceived Waiting Time, Information Delivery, and Expressive Quality on Patient Satisfaction in the Emergency Department. Annals of Emergency Medicine, 28, 657-665. https://doi.org/10.1016/S0196-0644(96)70090-2

[9] McCaig, L.F. and Nawar, E.W. (2006) National Hospital Ambulatory Medical Care Survey: 2004 Emergency Department Summary. No. 372, US Department of Health and Human Services, Centers for Disease Control and Prevention, National Center for Health Statistics, Atlanta.

[10] Graff, L.G. and Robinson, D. (2001) Abdominal Pain and Emergency Department Evaluation. Emergency Medicine Clinics of North America, 19, 123-136. https://doi.org/10.1016/S0733-8627(05)70171-1

[11] Chaudhury, H., Mahmood, A. and Valente, M. (2005) Advantages and Disadvantages of Single-Versus Multiple-Occupancy Rooms in Acute Care Environments a Review and Analysis of the Literature. Environment and Behavior, 37, 760-786. https://doi.org/10.1177/0013916504272658

[12] Abdullah, M.H. (2005) Study on Outpatients' Waiting Time in Hospital University Kebangsaan Malaysia (HUKM) through the Six Sigma Approach 1. The Journal of the Department of Statistics, 1, 39-53.

[13] McNew, R., Di Lima, S., Forsyth, J. and Gillis, J. (2000) Emergency Department Compliance Manual. Aspen Publishing, Gaithersburg. 
Submit or recommend next manuscript to SCIRP and we will provide best service for you:

Accepting pre-submission inquiries through Email, Facebook, LinkedIn, Twitter, etc. A wide selection of journals (inclusive of 9 subjects, more than 200 journals)

Providing 24-hour high-quality service

User-friendly online submission system

Fair and swift peer-review system

Efficient typesetting and proofreading procedure

Display of the result of downloads and visits, as well as the number of cited articles Maximum dissemination of your research work

Submit your manuscript at: http://papersubmission.scirp.org/

Or contact jbm@scirp.org 